\title{
Stability of apparent vertical and ocular countertorsion as a function of lateral tilt ${ }^{1}$
}

\author{
HELIAS A. UDO DE HAES ${ }^{2}$ \\ MAX-PLANCK-INSTITUT FÜR VERHALTENSPHYSIOLOGIE
}

In Experiment 1 the inter- and intraindividual variance of the apparent vertical was established as a function of lateral body tilt. Both quantities increased with increasing degree of tilt, with a maximum at the inverted positions (150-180 deg). Because the apparent vertical depends mainly on the stimulation of the statolith organs, the findings imply that these ongans become less effective in indicating the vertical. In Experiment 2 the ocular countertorsion reflex was recorded photographically, simultaneously with the measurement of the apparent vertical. This eye reflex, which also depends on the stimulation of the statolith organs, showed no change in variance level at body positions from 30 to $180 \mathrm{deg}$. The result is discussed with respect to the origin of the change in effectiveness of the statolith organs.

The position of a luminous line that is perceived as vertical is referred to as the "apparent vertical" (AV); we will deal here with the AV in the absence of a visual framework. Two aspects can be measured: its direction and its stability (variance). For a physiological approach it is appropriate to measure the direction, not relative to gravity, but relative to the subject (see Fig. 1). The angle between the $A V$ and the subject is a function of lateral body tilt. It has been shown that this depends mainly on the stimulation of the statolith (or otolith) organs (Schöne, 1962, 1964; Correia et al, 1965; Graybiel \& Clark, 1965; Miller \& Graybiel, 1966b; Schöne et al, 1967; Graybiel et al, 1968).

Also the stability of the AV is a function of the degree of tilt. It is highest in the normal upright position, and declines with increasing degree of tilt (Nagel, 1898; Quix \& Eijsvogel, 1929; Brown, 1961; Miller \&

Fig. 1. Inset figure: Body position as stimulus and apparent vertical (AV) as response, measured in relation to the $S$; GV: gravitational vertical. Main figure: Apparent vertical as a function of body position for $13 \mathrm{Ss}$; each entry represents the mean of at least two (in the average seven) test means (at least 64 single values). Points under the dotted line represent A-phenomenon, points over this line E-phenomenon.
Graybiel, 1963a; Schöne, 1964; Colenbrander, 1964; Schöne \& Udo de Haes, 1968). It has been inferred that this decrease of stability might indicate a decline of the effectiveness of the statolith organs (Quix \& Eijsvogel, 1929; Graybiel \& Patterson, 1955; Brown, 1961; Graybiel \& Clark, 1962; Schöne, 1962, 1964).

This hypothesis has been supported by investigations on the influence of nonstatolithic stimulation: somesthetic (Schöne \& Udo de Haes, 1968), semicircular canal (von Holst \& Grisebach, 1951; Udo de Haes \& Schöne, in press) and visual (Bischof \& Scheerer, in press; Udo de Haes, in preparation) stimulation all exerted a stronger influence on the $\mathrm{AV}$ in the range of inverted, as compared to the range of normal body positions.
The aim of the present experiments was to investigate the origin of these changes in effectiveness. Therefore more precise measurements were performed of the stability of two responses, both dependent on the statolith organs, but involving different levels of neural organization: the AV and the ocular countertorsion reflex; the former involving complex perception processes, the latter being a more direct reflection of statolith organ activity (Woellner \& Graybiel, 1959; Schöne, 1962; Miller \& Graybiel, 1963b; Colenbrander, 1964; Kellogg, 1965).

\section{Method}

\section{EXPERIMENT 1}

Apparatus. The equipment for controlling lateral tilt (see Fig. 3a) was the

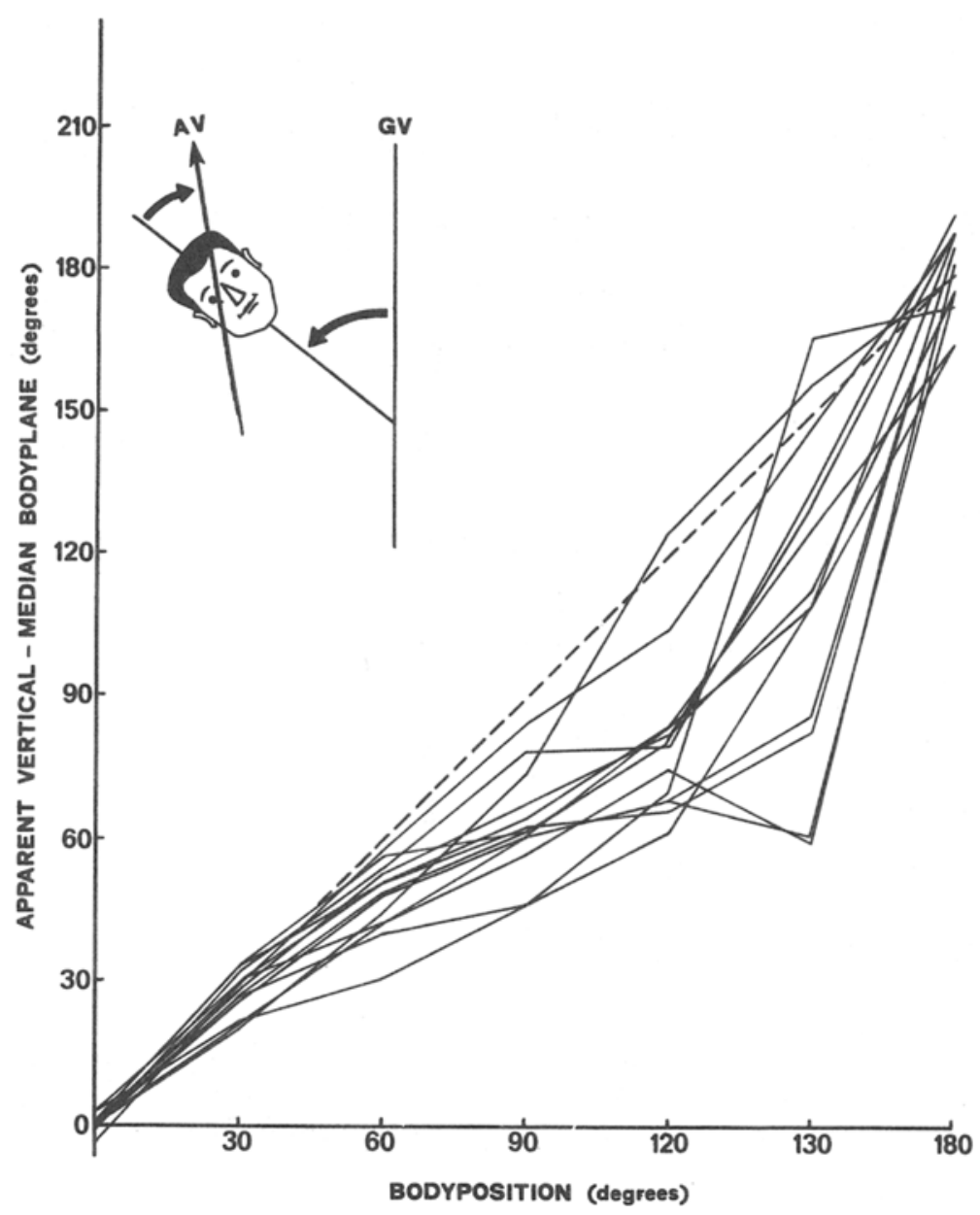

Copyright 1970, Psychonomic Journals, Inc., Austin, Texas 
Table 1

Mean Apparent Vertical (Deg) of 13 Ss with Inter-Subject Variance as a Function of Bodyposition

\begin{tabular}{|c|c|c|c|c|c|c|c|}
\hline & \multicolumn{7}{|c|}{ Bodyposition (Deg) } \\
\hline & 0 & 30 & 60 & 90 & 120 & 150 & 180 \\
\hline Mean AV of $13 \mathrm{Ss}$ & 0.4 & 27.5 & 47.7 & 63.7 & 80.9 & 114.3 & 180.6 \\
\hline Inter-Subject Variance & 0.3 & 1.6 & 4.3 & 9.4 & 22.8 & 89.1 & 6.3 \\
\hline
\end{tabular}

same as that described earlier (Udo de Haes \& Schöne, in press).

Subjects. Thirteen Ss were used (six men and seven women); all but one, aged 47 , were between 16 and 30 years old.

Procedure. S was rotated with eyes closed, in a dark environment, to the required position. He then adjusted a luminous line to apparent verticality at 15 -sec intervals for $8 \mathrm{~min}$. Between the adjustments the line was moved to and fro. After each 8-min test $\mathrm{S}$ was released from the apparatus and waited up to $5 \mathrm{~min}$ before the next test started. All Ss underwent at least two (in the average six to eight) tests in the following positions: 0 (head up), 30, 60, 90, 120, 150, and $180 \mathrm{deg}$ (head down). The material from different experimental series was used, resulting in the varying number of tests per $S$; however, the attention is directed mainly to the analysis of the data from the individual Ss.

Variance calculation. The inter- as well as intraindividual variance of the $\mathrm{AV}$ has been established. The latter concerns the variance within the single 8 -min tests. It has been shown that the AV during prolonged tilt changes (Müller, 1916; Miller \& Graybiel, 1963a; McFarland \& Clarkson, 1966; Schöne \& Udo de Haes, 1968). In order to overcome the influence of this factor on the variance calculation, the variance of the differences between successive adjustments was computed.

\section{Results}

The AV is plotted as a function of body position separately for the $13 \mathrm{Ss}$ in Fig 1. The variability between the curves increases with increasing degree of tilt; it is obviously highest at $150 \mathrm{deg}$. The intersubject variance values, as calculated from these data, are presented in Table 1.

The intrasubject (intratest) variance is plotted in Fig. 2 as a function of body position for the 13 Ss. It also increases with increasing degree of tilt, reaching a maximum for most, but not for all, Ss at $150 \mathrm{deg}$. At the 180-deg position many Ss produced again more stable adjustments.

Fig. 2. Intratest variance of apparent vertical as a function of body position for 13 Ss. The curves are based on the same material as presented in Fig. 1 b; each entry is the mean of, on the average, seven variance values.

simultaneously (see Fig. 3a). In order to deal with the two responses as independent quantities, the $\mathbf{A V}$ was more correctly measured relative to the eye and not to the head (see Fig 3b; cf. Colenbrander, 1964). We used normal photography; infrared photography, as used by Brandt and Fluur $(1966,1967)$ is not accurate enough for the present purpose. The right eye was photographed on ADOX KB 14 film with a

Method

\section{EXPERIMENT 2}

Apparatus. In this experiment $\mathrm{AV}$ and ocular countertorsion were measured

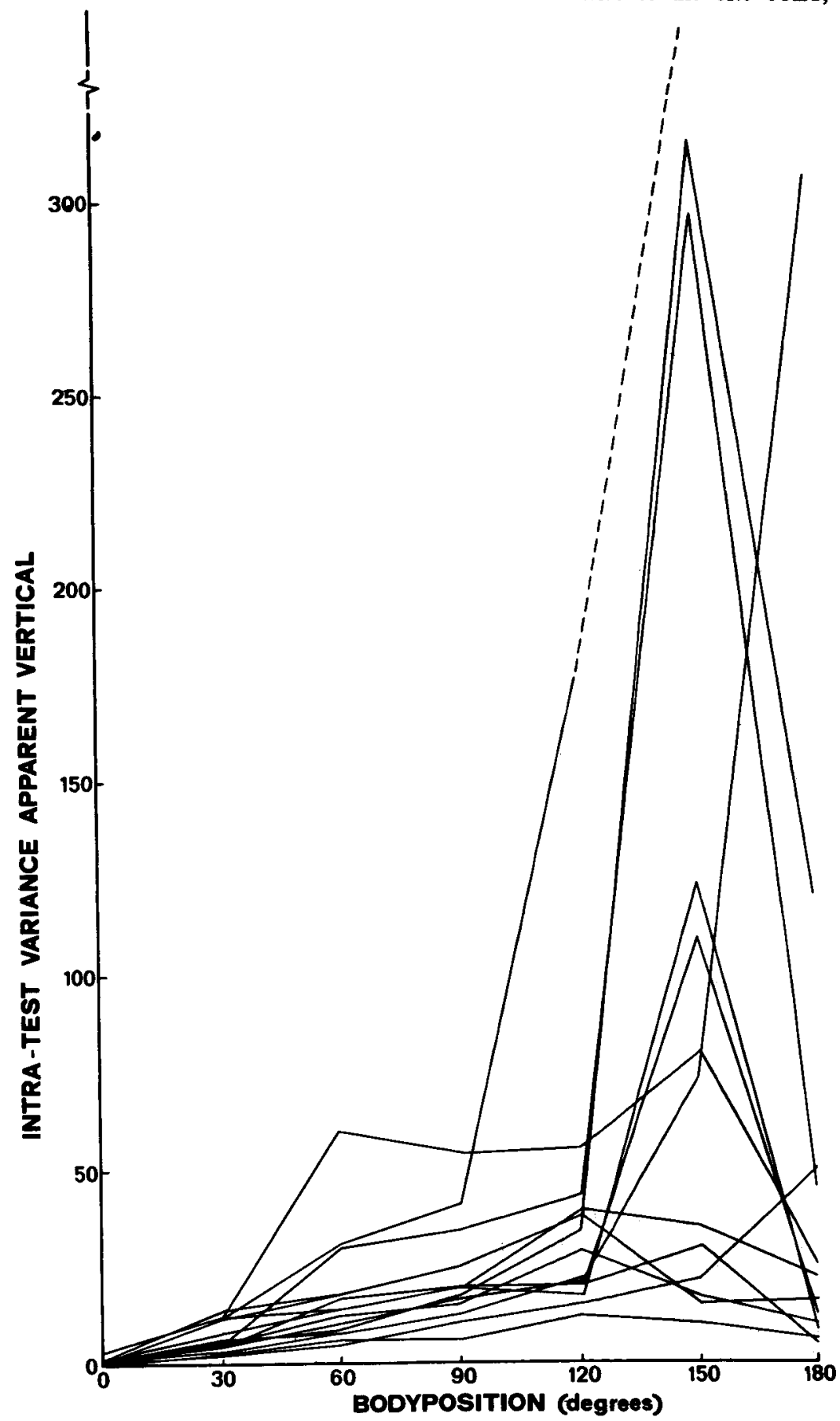


a)

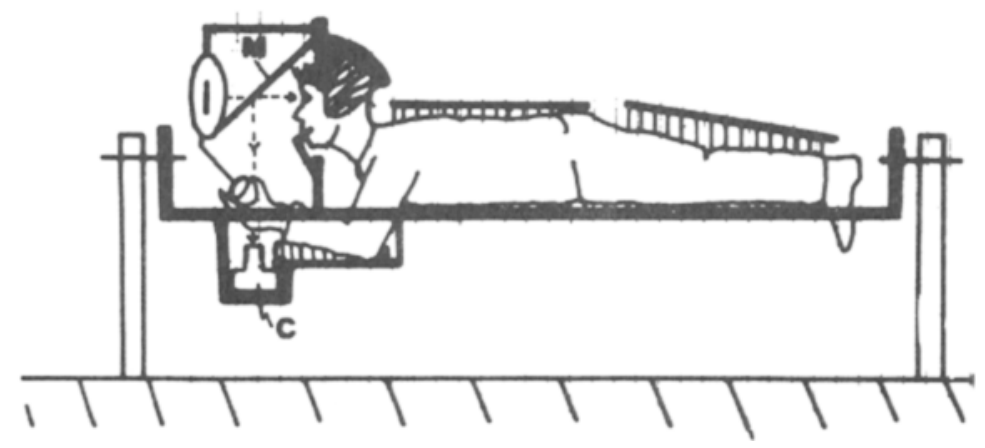

b)

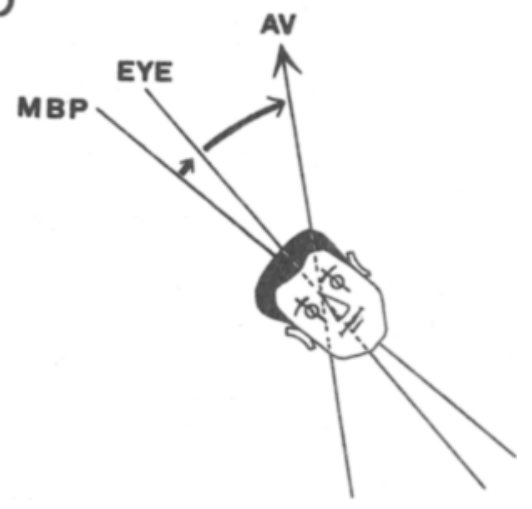

which the head of $S$ was very rigidly tixated. Two flashes, provided with a green filter, were placed on both sides of the head, in order to prevent blinding of the fovea. Illumination of the surroundings was avoided.

Subjects. Two Ss were engaged in this experiment, one man (27) and one woman (30).

Procedure. The procedure was essentially the same as that of Experiment 1 , apart from the photographing. The release of the camera was performed by $\mathrm{S}$. The first photograph was made in the first sec after reaching the position; thereupon a shot was taken every 15 sec directly after each adjustment of the line. The afterimages of the flashes vanished before the next adjustment. During the exposures a tiny light mark was fixated. The positions were $0,30,60,90$, 120,150 , and $180 \mathrm{deg}$, both to the left and right. In each of them every $S$ underwent

Fig. 4. The ocular countertorsion as a function of body position for two Ss. Of S2 not all films could be evaluated for technical reasons. (+) first values and (o) test means, both averages of generally four values; the data of a few preliminary tests are included. Fig. 3. (a) Apparatus, ad apted for discrepancies of $0.05-0.08 \mathrm{deg}$. The overall countertorsion photography simultaneously error of the measurement of the eye with the adjustment of a line to the apparent vertical. The eye is photographed with the camera (C) over a one-way mirror (M) through which the luminous line can be seen; the flashes are not shown in the figure. (b) Angle between apparent vertical and median body plane (MBP) as the sum of ocular countertorsion (MBP-eye) and angle eye-apparent vertical.

four tests; $180 \mathrm{deg}$ was reached twice after left and twice after right rotation. This makes up 48 tests per $S$, each of them with 32 paired observations. The test order was

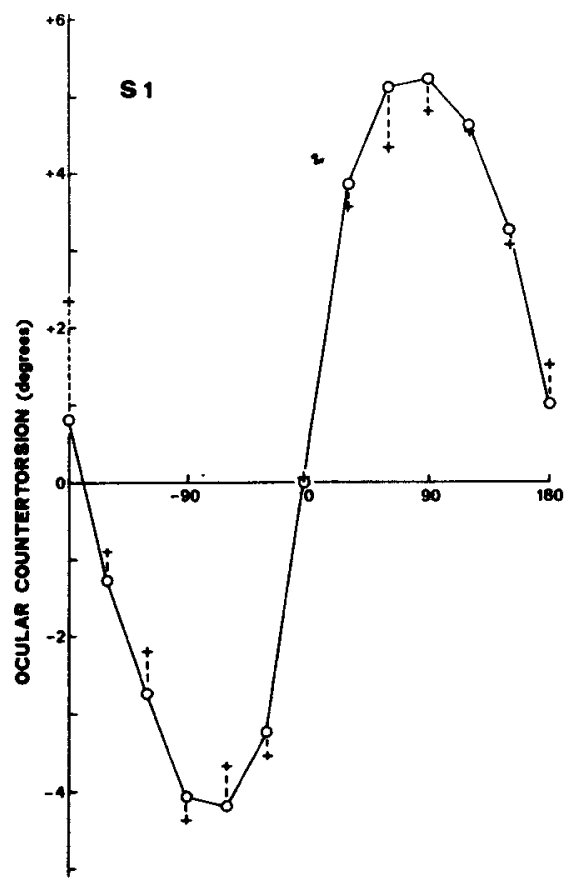

randomized, as well as the starting position of the luminous line.

Evaluation of the films. The negatives were projected with sixfold enlargment on a screen, which was rotatable and could slide from left to right. A fine line on it had to be aligned with two points of the episcleral veins of the eye. It was insured that no conjunctival veins were measured, because these lagged with increasing torsion and greater fluctuations in the eye position. Two points of the veins were chosen at approximately the same distance from the iris, in order to avoid "false torsion" (cf. Howard \& Evans, 1963). The angles could be read by means of a protractor scale; the edge of the film was used as reference. Reproducable measuring was possible with up to $0.10 \mathrm{deg}$ accuracy. Every photograph was measured twice and the average formed. Measurements of the error of the film transmission gave average position therefore lies in the order of $0.10-0.15$ deg.

\section{Results}

The countertorsion values (both 8-min means and first values) are plotted in Fig. 4 for the two Ss. The countertorsion of S1 did not change in time systematically. The values of S2, however, clearly showed a decrement in time; this was not accompanied by comparable changes in the simultaneously recorded AV.

The intratest variance of both countertorsion and $\mathrm{AV}$ is presented for the two Ss in Fig. 5. The AV variance of S1

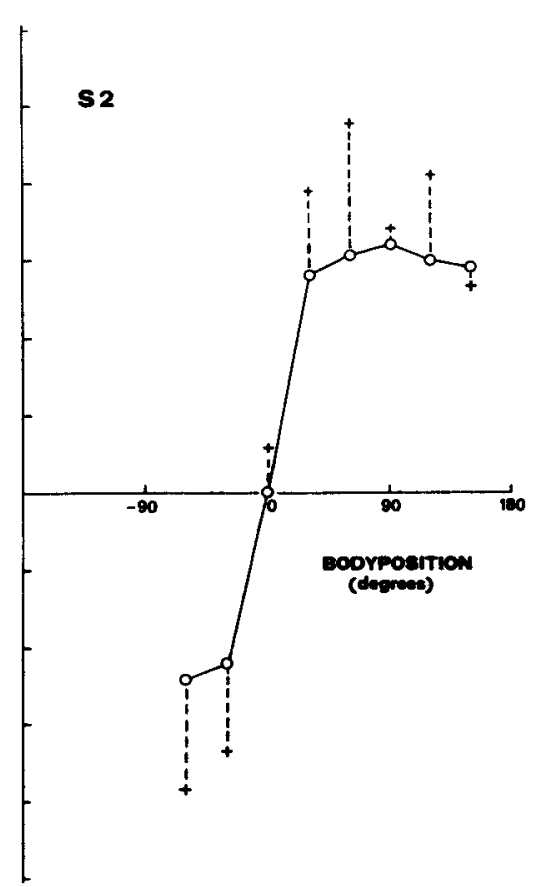




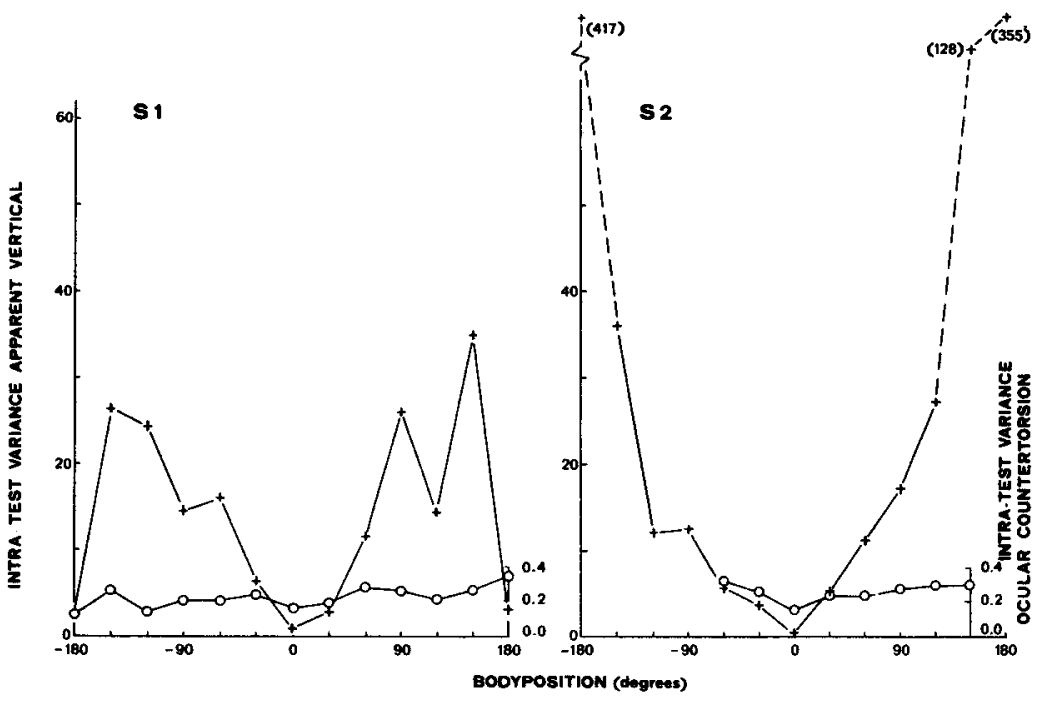

(Fig. 5a) reached a maximum at the 150-deg positions; the countertorsion variance showed only a slight left-right asymmetry, which seems to include the two 180-deg positions. The AV variance of $\mathrm{S} 2$. (Fig. 5b) reached a maximum at $180 \mathrm{deg}$. The countertorsion variance of this $\mathrm{S}$ was especially small at $\mathbf{0 ~ d e g}$, but showed no further change at the other positions.

A survey of the countertorsion variance values of both Ss is given in Fig. 6, with the results of the left- and right-hand body positions combined. At $\mathbf{0}$ deg the variance

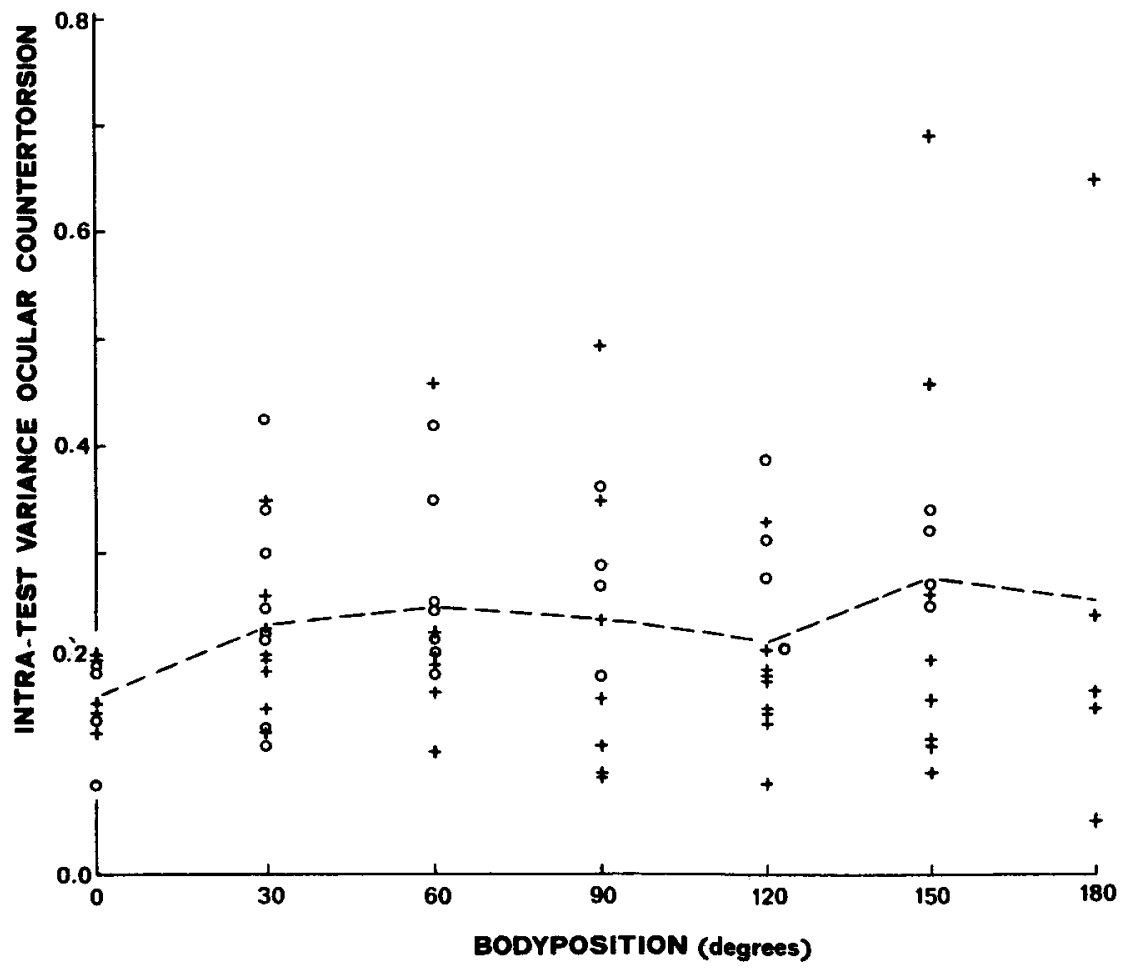

F ig. 5. Intratest variance of apparent vertical ( + ) and countertorsion (o) as a function of body position for two Ss; each entry is the average of generally four values.

\section{DISCUSSION}

The intraindividual (intratest) variance of the AV increases evenly for all Ss from 0 to $90 \mathrm{deg}$, thus confirming earlier investigations (cf. introduction). From 90 deg onwards, a markedly heterogeneous picture is acquired. Most Ss manifest, however, minimal stability at 150 or $180 \mathrm{deg}$ of tilt. Especially at $150 \mathrm{deg}$, large variance values were obtained. At $180 \mathrm{deg}$ the AV approximately coincides with the median plane of the body; this may offer some "hold" for adjusting the line and render for some Ss the adjustments more stable (see Fig. 2; cf. Fischer, 1930; Graybiel \& Clark, 1962; Miller \& Graybiel, 1966a).

The intratest variance of the AV shows how the inferred effectiveness of the statolith organs (see introduction) changes with body tilt over the whole range from head up to head down. The variability between the Ss, although less directly connected with the stability of the AV, showed the same trend.

The variance of the ocular countertorsion was smaller at 0 deg than at the other body positions. This, first of all, shows that the measuring procedure was accurate enough to establish differences in the variance of the countertorsion. The cause of the greater stability of the eye in the upright position of the body is not quite clear; it may be due to a more regular statolithic afference (see below), or to a more stable functioning of the eye musculature in this position.

From 30 to 180 deg of tilt the increase in the AV variance was not accompanied by an increase in the countertorsion variance (Fig. 5). This indicates that the inferred declining effectiveness is not caused by a malfunctioning of the statolith organs at the inverted positions.

Such a peripheral explanation is rendered unlikely also by recent electrophysiological findings of Trincker on the steadiness of the firing rate of utricular afferents (Trincker, in press). The steadiness did slightly decrease with increase of tilt up to $90 \mathrm{deg}$, but at further degrees of tilt it significantly improved again. These changes in steadiness,

Fig. 6. Single countertorsion intratest variance values as a function of body position; left- and right-tilt data are combined. (+) S1, (o) S2. 


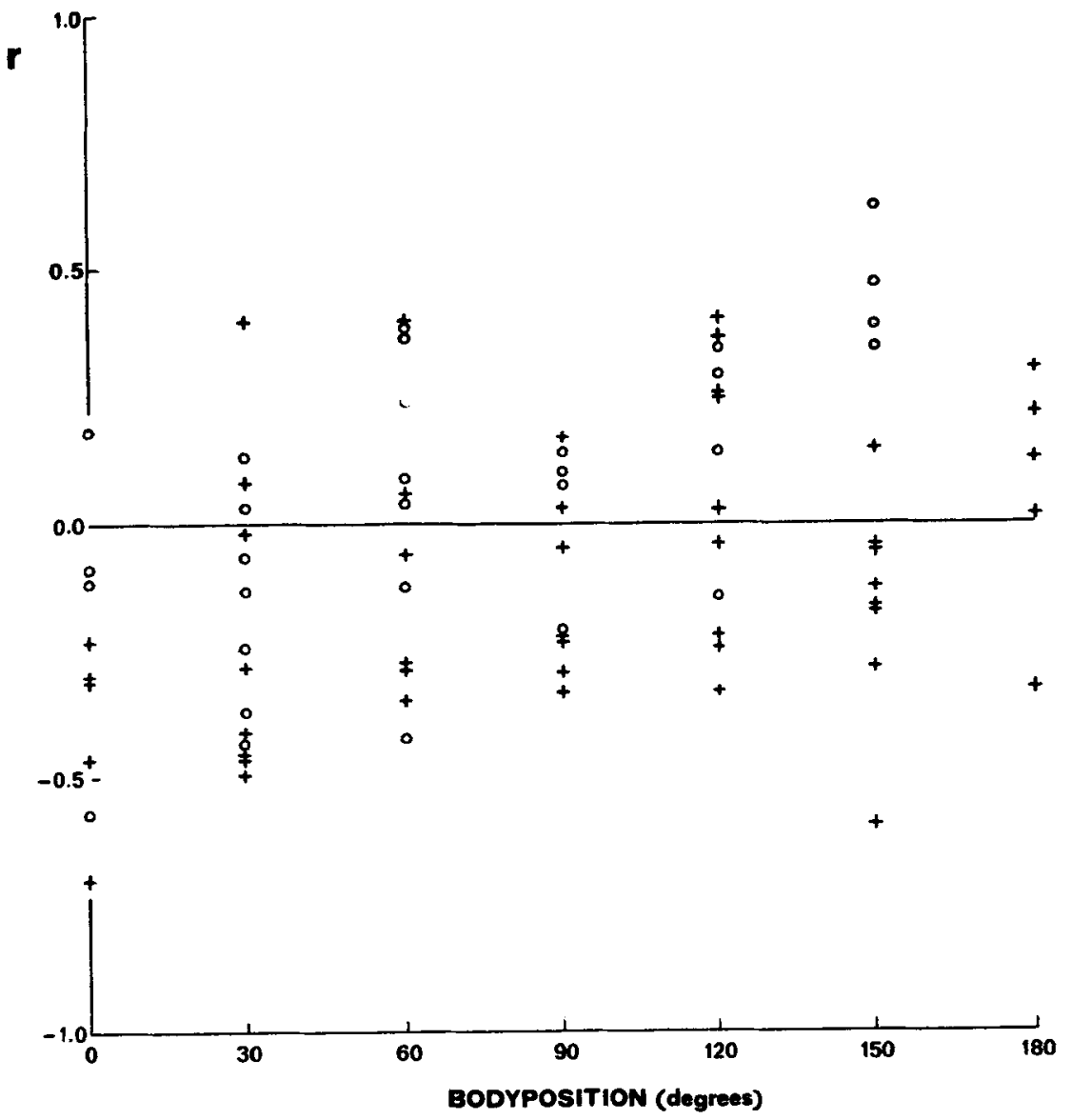

therefore, cannot be the cause of the changes in effectiveness as expressed in the perception of the vertical.

A few remarks may be added on the connection between AV and countertorsion. Although this eye reflex is vestigial in man, it still has to be regarded as a contribution to vertical constancy (Colenbrander, 1964; Bischof, 1966): When the head is tilted it reduces the rotation of the visual image on the retina. It would therefore be devoid of any biological significance, if the perception of the vertical would be corrected for the ocular countertorsion (Peters, 1969).

Another question is whether or not the AV is corrected for small fluctuations of the eye position, which are not related to the stimulation of the statolith organs. A slight negative correlation between countertorsion and $\mathbf{A V}$, when measured relative to the eye, was found at the upright position (Fig. 7). This could suggest that such a correction indeed might occur (cf. Colenbrander, 1964). However, more data would clearly be needed to establish the existence of this rather puzzling phenomenon.
Fig. 7. Intratest correlation coefficient (r) between apparent vertical (relative to eye) and countertorsion as a function of body position; values of left- and right-tilt are combined. (+) S1, (o) S2.

$360^{\circ}$. 2. Mitt. Untersuchungen an Normalen. Gracfes Archiv für Ophthalmologie, 1930, 123, 476-508.

GRAYBIEL, A., \& CLARK, B. Perception of the horizontal or vertical with the head upright, on the side, and inverted under static conditions, and during exposure to centripetal force. Aerospace Medicine, 1962, 33, 147.155.

GRAYBIEL, A., \& CLARK, B. Validity of the oculogravic illusion as a specific indicator of otolith function. Aerospace Medicine, 1965, 35, 1173-1181.

GRAYBIEL, A., MILLER, E. F. II, NEWSOM, B. D., \& KENNEDY, R. S. The effect of water immersion on perception of the oculogravic illusion in normal and labyrinthine-defective subjects. Acta Otolaryngologica, 1968, 65, 599-610.

GRAYBIEL, A., \& PATTERSON, J. L. Thresholds of stimulation of the otolith organs as indicated by the oculogravic illusion. Journal of Applied Physiology, 1955, 7, 666-670.

HOLST, E. von, \& GRISEBACH, E. Einfluss des Bogengangsystems auf die "subjektive Lotrechte" beim Menschen. Die Naturwissenschaften, 1951, 38, 67-68.

HOWARD, I. P., \& EVANS, J. A. The measurement of eye torsion. Vision Research, $1963,3,447-455$.

KELLOGG, R. S. Dynamic counter rolling of the eye in normal subjects and in persons with bilateral labyrinthine defects. In The role of the vestibular organs in the exploration of space. NASA SP-77, 1965, 195-202.

McFARLAND, J. H. \& CLARKSON, F Perception of orientation: Adaptation to lateral body-tilt. American Joumal of Psychology, 1966, 79, 265-271.

MILLER, E. F. II, \& GRAYBIEL, A. Rotary autokinesis and displacement of the visual horizontal associated with head (body) position. Aerospace Medicine, 1963a, 34 915-919.

MILLER, E, F, II, \& GRAYBIEL, A. A comparison of ocular counterrolling movements between normal persons and deaf subjects with bilateral labyrinthine defects. Annals of Otology, Rhinology, and Laryngology, 1963b, 72, 885-893.

MILLER, E. F. II, \& GRAYBIEL, A. Role of the otolith organs in the perception of horizontality. American Journal of Psychology, 1966a, 79, 24-37.

MILLER, E. F. II, \& GRAYBIEL, A. Magnitude of gravitoinertial force, an independent variable in egocentric visual localization of the horizontal. Journal of Experimental Psychology, 1966b, 71, 452-456.

MƯLLER, G. E. Über das Aubertsche Phanomen. Zeitschrift fur Psychologie und Phy siologie der Sinnenorgane, 1916, 49, 109-246.

NAGEL, W. A. Über das Aubertsche Phänomen und verwandte Tauschungen is ber die vertikale Richtung. Zeitschrift fur Psychologie und Physiologie der Sinnesorgane, 1898, 16, 373-398.

PETERS, R. A. Dynamics of the vestibular system and their relation to motion perception, spatial disorientation, and illusions. NASA CR-1309, 1969, 1-223.

QUIX, F. H., \& EIJSVOGEL, M. H. P. M. 
Experimente :̈ber die Funktion des Otolithenapparates beim Menschen. Zeitschrift für Hals-, Nasen- und Ohren-Heilkunde, 1929, 23, 68-96.

SCHÖNE, H. Ueber den Einfluss der Schwerkraft auf die Augenrollung und auf die Wahmehmung der Lage im Raum. Zeitschrift fur vergleichende Phy siologie, 1962, 46, 57-87.

SCHÖNE, H. On the role of gravity in human spatial orientation. Aerospace Medicine, 1964, 35, 764-772.

SCHONE, H., PARKER, D. E., \& MORTAG, H. G. Subjective vertical as a function of body position and gravity magnitude. Die Naturwissenschaften, 1967, 54, 288.

SCHONE, H., \& UDO DE HAES, H. A. Perception of gravity-vertical as a function of head and trunk position. Zeitschrift für vergleichende Physiologie, 1968, 60, 440-444.
SIEGEL, S. Nonparametric statistics for the behaviora] sciences. New York: McGraw-Hill, 1956.

TRINCKER, D. Vestibularapparat. In: 0000000

(Ed.) Lehrbuch der Physiologie in zusammenhängenden Einzeldarstellungen. Berlin: Springer, in press.

UDO DE HAES, H. A. Interaction between visual and gravireceptor stimulation with respect to the apparent vertical. In preparation.

UDO DE HAES, H. A., \& SCHÖNE, H Interaction between semicircular canals and statolith organs on apparent vertical and nystagmus. Acta Otolaryngologica, in press.

WADE, N. J. Visual orientation during and after lateral head, body, and trunk tilt. Perception \& Psychophysics, 1968, 3, 215-219.

WTKIN, H. A., \& ASCH, S. E. Studies in space orientation. III. Perception of the upright in the absence of a visual field. Journal of Experimental Psychology, 1948, 38, 603-614.

WOELLNER, R. C., \& GRA YBIEL, A. Counterrolling of the eyes and its dependerice on the magnitude of gravitational or inertial force acting laterally on the body. Journal of Applied Phy siology, 1959, 14, 632-634.

\section{NOTES}

1. The author wants to express thanks to Dr. Schone for the valuable discussions and to the author's wife for her technical assistance.

2. Address: Zoological Laboratory, Kaiserstraat, 63, Leiden, Holland.

(Accepted for publication October 20, 1969). 